\title{
COVID-19 testing acceptability and uptake amongst the Rohingya and host community in Camp 21, Teknaf, Bangladesh
}

Catherine R. McGowan ${ }^{1,2^{*}}$ (D), Nora Hellman', Sayem Chowdhury ${ }^{3}$, Abdul Mannan $^{3}$, Katherine Newell ${ }^{1}$ and Rachael Cummings ${ }^{1}$

\begin{abstract}
Facility-based sentinel testing for COVID-19 was implemented in May 2020 to monitor the prevalence of COVID-19 amongst the Rohingya and host community in Cox's Bazar, Bangladesh. In response both to low uptake of testing across all camps, and rumours of an outbreak of an influenza-like illness in May/June 2020, the International Organization for Migration (in partnership with ACAPS) undertook a qualitative study to collect accounts from the Rohingya relating to testing and treatment, and to explore the possibility that what was thought to be an outbreak of influenza may have been COVID-19. The report provided rich descriptions of the apprehension around testing and offered some clear recommendations for addressing these. We developed a testing 'script' in response to these recommendations, deploying it alongside a survey to determine reasons for declining a test. We compared testing uptake before deploying the testing script, and after (controlling for the total number of consultations), to generate a crude measure of the impact of the script on testing uptake. We coded reasons for declining a test thematically, disaggregated by status (Rohingya and host community) and sex. Despite the small sample size our results suggest an increase in testing uptake following the implementation of the script. Reasons provided by patients for declining a test included: 1) fear, 2) the belief that COVID-19 does not exist, that Allah will prevent them from contracting it, or that their symptoms are not caused by COVID-19, 3) no permission from husband/family, and 4) a preference to return at a later time for a test. Our findings largely mirror the qualitative accounts in the International Organization for Migration/ACAPS report and suggest that further testing amongst both populations will be complicated by fear, and a lack of clarity around testing. Our data lend force to the recommendations in the International Organization for Migration/ACAPS report and emphasise that contextual factors play a key role and must be considered in designing and implementing a health response to a novel disease.
\end{abstract}

Keywords: COVID-19, Infectious diseases, Forcibly Displaced Myanmar Nationals, FDMN, Sentinel testing, Rohingya, Acceptability, Testing uptake

\footnotetext{
* Correspondence: c.mcgowan@savethechildren.org.uk

'Humanitarian Public Health Technical Unit, Save the Children UK, 1 St John's Lane, London EC1M 4AR, UK

${ }^{2}$ Department of Public Health, Environments \& Society, London School of Hygiene \& Tropical Medicine, 15-17 Tavistock Place, London WC1H 9SH, UK Full list of author information is available at the end of the article
}

(c) The Author(s). 2020 Open Access This article is licensed under a Creative Commons Attribution 4.0 International License, which permits use, sharing, adaptation, distribution and reproduction in any medium or format, as long as you give appropriate credit to the original author(s) and the source, provide a link to the Creative Commons licence, and indicate if changes were made. The images or other third party material in this article are included in the article's Creative Commons licence, unless indicated otherwise in a credit line to the material. If material is not included in the article's Creative Commons licence and your intended use is not permitted by statutory regulation or exceeds the permitted use, you will need to obtain permission directly from the copyright holder. To view a copy of this licence, visit http://creativecommons.org/licenses/by/4.0/ The Creative Commons Public Domain Dedication waiver (http://creativecommons.org/publicdomain/zero/1.0/) applies to the data made available in this article, unless otherwise stated in a credit line to the data. 


\section{Introduction}

There are currently 860,494 Rohingya in Cox's Bazar, Bangladesh [1]. In addition, there are an estimated 335, 900 individuals in the host community [2]. Save the Children International (SCI) currently operates one Primary Health Care Centre (PHCC), eight health posts, and a newly constructed Severe Acute Respiratory Infection Isolation and Treatment Centre (SARI ITC) to serve both Rohingya and host communities. In response to growing concern about the potential for COVID-19 to cause significant morbidity and mortality, WHO and the Bangladesh Ministry of Health established eight sentinel testing sites for COVID-19, including the SCI PHCC. The initial protocol (dated 24. May 2020) required that anyone presenting at a sentinel site with any symptom of acute respiratory illness (ARI) be offered a COVID-19 test. Patients consenting to a test would be asked to isolate at the sentinel site until the test result was available (approximately $48 \mathrm{~h}$ ). On 11 June 2020, in response to low testing uptake, the Bangladesh Refugee Relief and Repatriation Commissioner (RRRC) decided to allow patients to return home while their test was being processed; however, uptake of testing for COVID-19 at the PHCC (and across all sentinel sites) remained low [3].

In response to low uptake of testing across all camps as well as reports of an outbreak of an influenza-like illness in the camps in May/June and the absence of a corresponding increase in primary healthcare consultations the International Organization for Migration (IOM), in partnership with ACAPS, undertook a qualitative study to collect accounts from Rohingya around testing and treatment, and to explore the possibility that what was thought to be an outbreak of influenza may have been COVID-19. The report, which was based on interviews collected by Rohingya researchers between 25 May and 25 June 2020, explored reasons for the low uptake of testing. The report suggested that, "[a] general consensus seemed to have formed in the community not to test and to avoid seeking treatment" ([4], p. 2). The report further highlighted that the Rohingya's reasons for not engaging in testing were many and included: rational concerns about being asked to remain at a health facility for two days to await test results, lack of clarity about the testing process (including why they were being asked to undergo testing), fear of lockdown of entire sub-blocks as a result of a positive test, concerns about incidents involving disclosure of patient details and test results to the public, and a lack of clarity on the benefits of testing [4].

Therefore, to increase testing uptake, and understand testing acceptability, we created a script (Fig. 1) - addressing concerns raised in the IOM/ACAPS report - for health care workers (HCW) to read to patients. In addition, we asked HCWs to record some basic demographic information about patients who were offered a test and, if they declined, to document the reason for refusal. As the report cautioned against pressuring patients for information, we designed the survey to be brief and unintrusive.

\section{Methods}

The testing script was developed by the SCI Public Health Director and the Monitoring, Evaluation, Accountability and Learning (MEAL) Manager for the Cox's Bazar COVID-19 response. With the support of the PHCC Medical Officer and the Laboratory Technician we trained PHCC staff on communicating the content of the testing script (both in Bangla and Chittagonian) and on the collection of the survey data. We deployed our testing script and survey using Kobo Toolbox (Harvard Humanitarian Initiative, Cambridge, MA). The survey was designed to collect age, status (Rohingya or host community), and whether or not the patient had agreed to a test. We also collected information on the acceptability of testing by asking those who

We would like to give you a test for COVID because you have [mention symptom]. The test involves putting a small piece of cotton in your nose and another in your mouth to collect a sample; the test will not hurt, and it is very fast. Your test will show if you have COVID or not. If your test is positive, we will come to your home to tell you; we will only discuss this with you, and not with anyone else unless you ask us to. Most people who have COVID do not get very sick, but we may offer you some medicine to help you feel better. The results of the test take about two days to be sent to us; if you feel unwell in those two days and want us to help you, you are welcome to come back to the facility.

Fig. 1 Standard COVID-19 testing script 
had declined a test to indicate their reason for refusal. HCWs administered the test with support from a translator if required. No fields were mandatory, and staff were requested not to put pressure on patients to explain their decision. We defined 'uptake' as the proportion of tests administered compared to the number of tests offered. We defined 'acceptability' as the qualitative justification for declining a test. We coded the reasons for declining a test thematically. We used routinely collected data for total consultations, combined with testing data, to determine change in uptake.

\section{Results}

We deployed the survey (see Table 1) between 9 July and 21 October 2020. Of the 222 patients who were offered a COVID-19 test 60\% $(n=133)$ were women, $61 \%$ were Rohingya $(n=136)$; just under half accepted the offer of a test $(n=113,51 \%)$. Of the 109 patients who refused a test, 26 (24\%) declined to provide a reason for doing so. The four most commonly cited reasons (comprising $88 \%$ of the responses) were: 1$)$ fear ( $n=27 ; n=$ 21 female; $n=23$ Rohingya), 2) does not believe in COVID-19, believes Allah will protect them from contracting COVID-19, or does not believe symptoms are due to COVID-19 $(n=25 ; n=17$ female, $n=18$

Table 1 Demographic characteristics and results

\begin{tabular}{lll}
\hline Age & & \\
Mean (SD) & $31(14.58)$ & \\
Median & 27 & \\
Range & $14-100$ & \\
Sex & & \\
Female & 133 & $60 \%$ \\
Male & 89 & $40 \%$ \\
Status & & \\
Rohingya & 136 & $61 \%$ \\
Host community & 86 & $39 \%$ \\
Agreed to test & & \\
Yes & 113 & $51 \%$ \\
No & 109 & $49 \%$ \\
Reason ( $n=83$ ) & & \\
Fear & 27 & $33 \%$ \\
$\begin{array}{l}\text { Does not believe in COVID-19; believes Allah } \\
\text { will protect her/him from COVID-19; does }\end{array}$ & 25 & $30 \%$ \\
not believe s/he has symptoms of COVID-19 & & \\
Husband/family will not allow; does not & 11 & $13 \%$ \\
have permission \\
Will come back later \\
Other (e.g. has already had test...) & $10 \%$ \\
\hline
\end{tabular}

Rohingya), 3) no permission from husband/family ( $n=$ 11; $\mathrm{n}=11$ female, $\mathrm{n}=11$ Rohingya), and patient will come back later ( $n=10 ; n=4$ female, $\mathrm{n}=4$ Rohingya).

Univariate analysis was performed using the chisquare test of independence to assess the hypothesis of association between the observed frequencies in the categorical variables of script use and test consent status in new consultations (see Fig. 2). We considered a $p$-value of $<0.05$ as statistically significant. The association between script use and test consent status was statistically significant, $X^{2}(1, N=6180)=49.2$ $p=<0.001$ with patients offered a testing script more likely to consent to COVID-19 testing.

\section{Discussion}

Our survey demonstrates that though our efforts to provide clarity and the necessary assurances around testing have significantly improved uptake, only half of eligible patients were willing to accept the offer of a COVID-19 test. Many patients declined to provide a justification for refusing a test; however, the justifications that were provided suggest: fear, poor understanding of COVID-19 susceptibility and symptoms, lack of an urgency around testing, lack of understanding of the benefits of testing (or low appeal of the benefits when compared to the risks), and an inability to consent to a test without permission from a family member (most often a husband). It is worth noting that responses indicating that patients did not believe they had COVID-19, or did not believe that their symptoms were indicative of COVID-19, may reflect the assumption that the outbreak had happened earlier in the year as suggested by the IOM/ACAPS report [4]. We also demonstrate that addressing Rohingya concerns by explaining the purpose of test improved uptake.

A key limitation to our study is its small sample size which may have increased the probability of Type 2 error. Furthermore, we accept that a range of responses (e.g. having already had a test, needing permission from husband/family, or promises to return later for a test) may proxy for fear or disinterest. However, the responses to our survey, regardless of their relative proportion and lack of statistical power, are notable in that they lend force to the findings of the qualitative accounts detailed in the IOM/ACAPS report which found that the Rohingya population went to great lengths to avoid being tested owing to historical fears of mistreatment by authorities and health actors, to more recent accounts of "...negative, stigmatising, undignified, and difficult experiences around the testing and treatment process" $[4,5]$. Finally, we have demonstrated that uptake of testing increased once we began providing standard, scripted assurances around the confidentiality of test results, and 


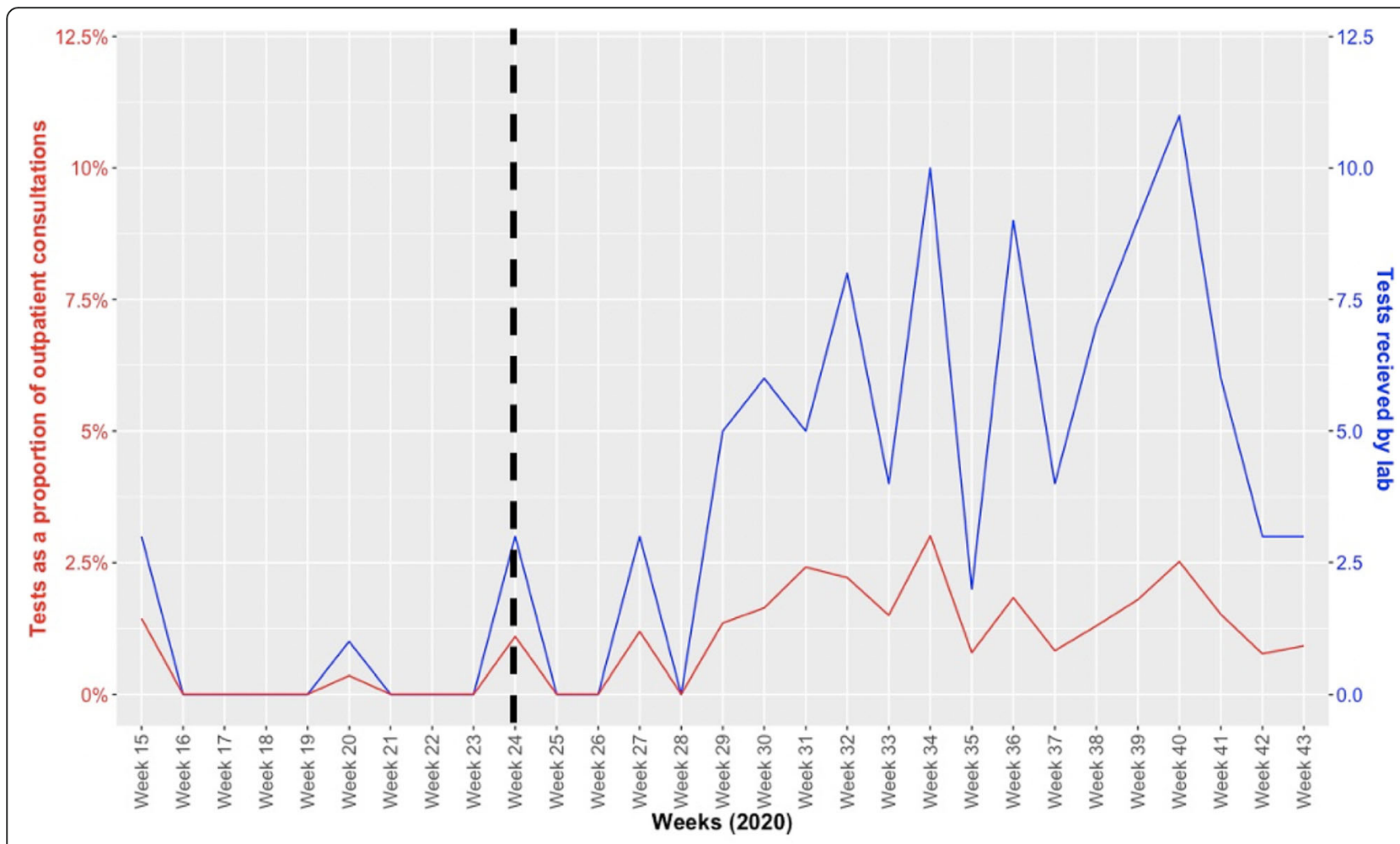

- - Testing script implemented

Fig. 2 Tests as a proportion of weekly outpatient consultations and tests received by the lab

information addressing some of the lack of clarity around the testing protocol.

\section{Conclusion}

The IOM/ACAPS report cautions that, "[a] general consensus seems to have formed in the community not to test" and that "applying more pressure or trying to "investigate' events may frighten people, resulting in their hiding or fleeing from such efforts" ([4], p. 2). Furthermore, various breaches of confidentiality early in the response have compounded mistrust around testing [4]. Further testing within this population to evidence the trajectory of the outbreak, and to establish if accounts of a rise in ARIs in the camps in May-June may have been COVID-19, would likely require a large-scale serosurvey. However, our survey suggests that challenges to testing are likely to persist unless considerable efforts are made to address rational fears around testing relating largely to the complex history of the Rohingya population, and to more proximal and immediate fears of lockdown or disclosure of test results. High vaccine uptake in the camps suggests that Rohingya/host populations may not be averse to sero-surveys provided their benefits are clearly communicated. Our experience of low uptake of COVID-19 testing amongst PHCC patients in Camp 21 underlines the importance of considering contextual factors when designing and implementing a health response, especially to a novel disease.

\section{Acknowledgements}

We would like to thank the staff at the Save the Children Primary Health Care Centre in Camp 21, Teknaf, Bangladesh. Thank you also to Noyem Uddin and David Kennedy for sending us additional testing data. Finally, thank you to Maheen Chowdhury for making everything possible.

\section{Authors' contributions}

Methods and survey design: CM/RC, Administration of survey: SC/AM, Drafting of manuscript: CM/SC/AM/NH/RC. The authors read and approved the final manuscript.

\section{Funding}

The COVID-19 response in Cox's Bazar was, in part, supported by the UK Foreign, Commonwealth \& Development Office.

\section{Availability of data and materials Not applicable.}

\section{Ethics approval and consent to participate}

We carried out this survey as part of programme evaluation. No ethics approval was required. No individual level, or otherwise identifiable, data are reported in this paper

\section{Consent for publication}

Not applicable.

\section{Competing interests}

The authors declare no competing interests. 


\section{Author details}

'Humanitarian Public Health Technical Unit, Save the Children UK, 1 St John's Lane, London ECIM 4AR, UK. ${ }^{2}$ Department of Public Health, Environments \& Society, London School of Hygiene \& Tropical Medicine, 15-17 Tavistock Place, London WC1H 9SH, UK. ${ }^{3}$ Save the Children Bangladesh, Rohingya Response, Cox's Bazar, Bangladesh.

Received: 15 September 2020 Accepted: 5 November 2020

Published online: 11 November 2020

\section{References}

1. United Nations High Commissioner for Refugees (UNHCR). Refugee Response in Bangladesh Geneva: UNHCR; 2020 [Available from: https:// data2.unhcr.org/en/situations/myanmar_refugees.

2. The United Nations Office for the Coordination of Humanitarian Affairs (OCHA). Host Communities Geneva: OCHA; 2020 [Available from: https:/www. humanitarianresponse.info/en/operations/bangladesh/host-communities.

3. World Health Organization (Bangladesh). Emergency: Rohingya Crisis (Situation Report \#11). Cox's Bazar: WHO; 2020. 24 June 2020.

4. International Organization for Migration (IOM). The Assessment Capacities Project (ACAPS). The stories being told: Rohingya report on the epidemic. Geneva: IOM and ACAPS; 2020. 13 July 2020.

5. International Organization for Migration (IOM). The Assessment Capacities Project (ACAPS). Have you ever walked a mile in their shoes. Geneva: IOM and ACAPS; 2020.

\section{Publisher's Note}

Springer Nature remains neutral with regard to jurisdictional claims in published maps and institutional affiliations.

- fast, convenient online submission

- thorough peer review by experienced researchers in your field

- rapid publication on acceptance

- support for research data, including large and complex data types

- gold Open Access which fosters wider collaboration and increased citations

- maximum visibility for your research: over $100 \mathrm{M}$ website views per year

At $\mathrm{BMC}$, research is always in progress. 